Article

\title{
Dose Reduction to the Swallowing Apparatus and the Salivary Glands by De-Intensification of Postoperative Radiotherapy in Patients with Head and Neck Cancer: First (Treatment Planning) Results of the Prospective Multicenter DIREKHT Trial
}

\author{
Marlen Haderlein ${ }^{1, *} \mathbb{C}$, Stefan Speer ${ }^{1}$, Oliver Ott $^{1}$, Sebastian Lettmaier ${ }^{1}$, Markus Hecht ${ }^{1}(\mathbb{D}$, \\ Sabine Semrau ${ }^{1}$, Benjamin Frey ${ }^{1}{ }^{1}$, Claudia Scherl ${ }^{2,3}$, Heinrich Iro ${ }^{3}$, Marco Kesting ${ }^{4}$ and \\ Rainer Fietkau ${ }^{1}$ \\ 1 Department of Radiation Oncology, Universitätsklinikum Erlangen, Friedrich-Alexander-Universität \\ Erlangen-Nürnberg (FAU), 91054 Erlangen, Germany; stefan.speer@uk-erlangen.de (S.S.); \\ oliver.ott@uk-erlangen.de (O.O.); sebastian.lettmaier@uk-erlangen.de (S.L.); \\ markus.Hecht@uk-erlangen.de (M.H.); sabine.semrau@uk-erlangen.de (S.S.); \\ benjamin.frey@uk-erlangen.de (B.F.); rainer.fietkau@uk-erlangen.de (R.F.) \\ 2 Department of Otorhinolaryngology, Universitätsklinikum Mannheim, Medical Faculty Mannheim, \\ University of Heidelberg, 68167 Mannheim, Germany; claudia.scherl@umm.de \\ 3 Department of Otorhinolaryngology, Universitätsklinikum, Friedrich-Alexander-Universität \\ Erlangen-Nürnberg (FAU), 91054 Erlangen, Germany; heinrich.iro@uk-erlangen.de \\ 4 Department of Oral and Maxillofacial Surgery, Universitätsklinikum, Friedrich-Alexander-Universität \\ Erlangen-Nürnberg (FAU), 91054 Erlangen, Germany; marco.kesting@uk-erlangen.de \\ * Correspondence: marlen.haderlein@uk-erlangen.de; Tel.: +49-9131-8543-025; Fax: +49-9131-8535-969
}

Received: 15 January 2020; Accepted: 20 February 2020; Published: 26 February 2020

\begin{abstract}
Aim: Evaluating radiotherapy treatment plans of the prospective DIREKHT trial (ClinicalTrials.gov, NCT02528955) investigating de-intensification of radiotherapy in patients with head and neck cancer. Patients and Methods: The first 30 patients from the DIREKHT trial of the leading study centre were included in this analysis. Standard treatment plans and study treatment plans derived from the protocol were calculated for each patient. Sizes of planning target volumes (PTVs) and mean doses to organs at risk were compared using the Student's t-test with paired samples. Results: Mean PTV3 including primary tumor region and ipsilateral elective neck up to a dose of 50 Gy in the study treatment plans was $662 \mathrm{~mL}(+/-165 \mathrm{~mL}$ standard deviation (SD)) and therefore significantly smaller than those of the standard treatment plans (1166 mL (+/- $266 \mathrm{~mL} \mathrm{SD).} \mathrm{In} \mathrm{the}$ medial and inferior constrictor muscles, cricopharyngeal muscle, glottic and supraglottic laryngeal areas, arytenoid cartilages, contralateral major salivary glands highly significant dose reductions $(p<$ 0.0001) of more than 10 Gy were achieved in study treatment plan compared to standard treatment plan. Conclusion: De-intensification of radiotherapy led to smaller planning target volumes and clinical relevant dose reductions in the swallowing apparatus and in the contralateral salivary glands.
\end{abstract}

Keywords: de-intensification; radiotherapy; head neck cancer; postoperative; ipsilateral elective neck irradiation only; salivary glands; swallowing apparatus

\section{Background}

To date, there is only one prospective study [1] with a small sample size and some retrospective studies [2,3] investigating the possibility of treating ipsilateral elective neck nodes only in the 
postoperative situation of head and neck cancer. Moreover, the primary tumor region usually is treated with a dose up to 64-66 Gy [4-6]. The sole study investigating dose reduction in patients with head and neck cancer undergoing postsurgical radiotherapy (RT) is Peters et al. [7] which showed that a minimal dose of 57.6 Gy should be applied even in low-risk patients. Risk classification was done by a point score leading to a possible inclusion of even patients with T4 tumors, major nerve infiltration or resection margin $<5 \mathrm{~mm}$ in the low-risk group.

In low-risk patient populations with head and neck cancer 5 year- locoregional control rates of over $90 \%$ have been achieved, but about $30 \%$ of the patients suffer from grade III therapy-related side-effects, like xerostomia, dysphagia and trismus leading to a reduced quality of life [8-13]. Therefore, a need for a prospective trial investigating de-intensification of radiotherapy is recognized in a clearly defined patient population with head and neck cancer in the postoperative situation.

The prospective, non-randomised, and multicenter DIREKHT-trial investigates the possibility of de-intensification of postoperative radiotherapy in a predefined low-risk patient population with head and neck cancer (ClinicalTrials.gov, NCT02528955).

Low-risk was specified as either low-risk for local recurrence in the primary tumor region or for occurrence of any contralateral neck lymph nodes. In case of low-risk for local recurrence of the primary tumor defined as $\mathrm{pT} \leq 2$, no peritumoral lymphatic vessel invasion (L0), no peritumoral perineural spread (Pn0) and a resection safety margin of $\geq 5 \mathrm{~mm}$, irradiation dose to the primary tumor region was reduced to a total dose of $56 \mathrm{~Gy}$. In patients with a genuine low risk for contralateral neck recurrence $(\leq \mathrm{p}$ T3,$\leq 3$ ipsilateral neck node metastases, contralateral no lymph node metastases defined as either $\mathrm{pN} 0$ or contralateral $\mathrm{cN} 0$ in case of well lateralized oral cavity or oropharyngeal carcinoma) prescribed target volume was reduced by electively irradiating only the ipsilateral neck nodes. This resulted in three protocol treatment arms (see Figure 1).

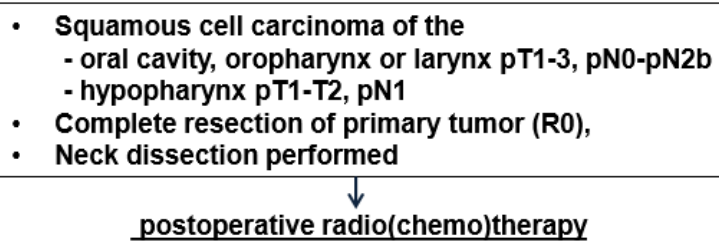

according to histology and type of surgery performed:

\begin{tabular}{|c|c|c|}
\hline Arm 1 & Arm 2 & Arm 3 \\
\hline $\begin{array}{l}\leq \mathrm{pT} 2, \mathrm{R} \geq 5 \mathrm{~mm}, \mathrm{LO}, \\
\text { Pn0 } \\
>3 \text { ipsilateral lymph } \\
\text { node metastases } \\
\text { or in case of } \\
\text { midline infiltration of } \\
\text { primary tumor: no } \\
\text { contralateral neck } \\
\text { dissection performed }\end{array}$ & $\begin{array}{l}>\mathrm{pT} 2 \text { or } \\
\mathrm{R}<5 \mathrm{~mm}, \neq \mathrm{LO}, \neq \mathrm{PnO} \\
\leq 3 \text { ipsilateral lymph } \\
\text { node metastases }{ }^{1}\end{array}$ & $\begin{array}{l}\leq \mathrm{pT} 2, \mathrm{R} \geq 5 \mathrm{~mm}, \mathrm{LO}, \\
\mathrm{Pn0} \\
\text { and } \\
\leq 3 \text { ipsilateral lymph } \\
\text { node metastases }^{1}\end{array}$ \\
\hline $\begin{array}{c}\text { Dose reduction in } \\
\text { primary tumor region } \\
\text { to } 56 \mathrm{~Gy}\end{array}$ & $\begin{array}{l}\text { Reduction of } \\
\text { irradiated volume } \\
\text { (only RT of the } \\
\text { ipsilateral elective } \\
\text { neck nodes) }\end{array}$ & $\begin{array}{l}\text { Dose reduction in } \\
\text { primary tumor region } \\
\quad \text { to } 56 \mathrm{~Gy} \\
\quad \text { and } \\
\text { Reduction of irradiated } \\
\text { volume (only RT of the } \\
\text { ipsilateral elective } \\
\text { neck nodes) }\end{array}$ \\
\hline
\end{tabular}

1: 1 : contralateral pNO ( $\geq 6$ dissected lymph nodes) or contralateral $\mathrm{cN} 0$ in case of strictly ipsilateral localized carcinoma of the oral cavity or oropharynx ( $\geq 5 \mathrm{~mm}$ distance from midline)

Figure 1. Flow Chart of the DIREKHT trial. 
Enrollment of patients in the leading study centre started in September 2014 and is ongoing. To date (30 November 2019) eight study centres are recruiting patients and 127 patients have been included. Inclusion of 200 patients in total is planned and because of the known different radiation response there is a stratification on human papilloma virus (HPV) status and also on tumor localisation.

The aim of the present analysis is to quantify size of irradiated target volumes and to quantify dose reduction in organs at risk, especially in the swallowing apparatus and salivary glands in study treatment plans compared to non-restricted standard treatment plans. Radiation doses of $56 \mathrm{~Gy}$ and more are known to cause fibrosis and for quality assurance it should also be assessed if a clinical relevant dose reduction of $<56$ Gy in the swallowing apparatus might be achieved or if the dose constraints of the study protocol might be improved.

\section{Material and Methods}

At the timepoint of the present analysis 30 patients of the leading study center of the DIREKHT trial (ClinicalTrials.gov, NCT02528955), the Department of Radiation Oncology at Universitätsklinikum Erlangen, have been included in the trial and were available for this treatment planning study. Additionally to the protocol-based irradiation plan, for each patient a standard treatment plan was calculated for dose comparisons.

The protocol was approved by the Human Research Protocol Office, and all patients gave signed informed consent to participate in the trial. All procedures were performed in accordance with the Helsinki Declaration.

\subsection{Target Volumes and Dose Prescriptions}

All target volumes were contoured on an intravenous contrast-enhanced planning computertomography (CT) on axial $3 \mathrm{~mm}$ slices with patients in supine position fixed with a thermoplastic mask system. Fusion of preoperative diagnostic imaging (usually CT, but also MRI or FDG-PET-CT) to the planning CT was done to define preoperative gross tumor volume (GTV). Additionally, surgery and pathology reports were taken into account.

According to study protocol target volumes and dose prescriptions were as follows:

Clinical target volume (CTV) 1 included the former primary tumor region or space after resection (if the criteria for dose reduction referred to in the introduction are not met) and lymph node levels with resected lymph node metastases with extracapsular spread (ECS) (in case of ECS or soft tissue deposits $\geq 3 \mathrm{~cm}$ the lymph node levels should have been surrounded by a $5 \mathrm{~mm}$ safety margin).

CTV 2 always included the former primary tumor region or space after resection, lymph node levels with resected lymph node metastases (in case of ECS or soft tissue deposits $\geq 3 \mathrm{~cm}$ the lymph node levels should be surrounded by $5 \mathrm{~mm}$ safety margin) and tracheostomy (either tracheostoma or former region of the tracheotomy performed during surgery).

CTV 3 additionally to CTV2 includes elective neck nodes (criteria for target volume reduction by only treating ipsilateral elective neck nodes are mentioned in the introduction section). For detailed information on contouring elective neck nodes see Table S1 in Supplementary Material.

PTV 1, 2 and 3 resulted by giving a safety margin of $3-5 \mathrm{~mm}$ around each CTV1, 2 and 3 . Size of safety margin $(3-5 \mathrm{~mm})$ is defined by each participating centre according to individual setup errors.

Prescribed dose in PTV 1 was 64 Gy, in PTV 256 Gy and in PTV 350 Gy. Single fraction dose was 2 Gy. One fraction per day and 5 fractions per week were delivered.

Target volume definition and dose prescriptions of the standard treatment plan were as follows:

CTV 1: elective neck nodes on both sides of the neck, administered dose using percutaneous radiotherapy (RT): 50 Gy; CTV 2: lymph node metastases without ECS, administered cumulative dose using percutaneous RT: 56 Gy; CTV 3: primary tumor bed and lymph node metastases with ECS, administered cumulative using percutaneous RT dose: 64 Gy.

For patients being treated in Arm 1 a PTV 1 including the primary tumor region was defined. For patients being treated in Arm 2 the PTV 3 was enlarged by including the contralateral elective neck 
nodes and for patients being treated inArm 3 a PTV 1 was defined and PTV 3 was enlarged. PTV 2 is the same in standard and study treatment plan.

\subsection{Organs at Risk}

The following swallowing structures were delineated according to Christianen et al. [14]: superior, medial and inferior constrictor muscles (PCMs), cricopharyngeal muscle (CPM), esophagus inlet muscle (EIM), glottic/supraglottic larynx and base of the tongue (BOT). Additional contouring of the cervical esophagus (up to the superior border of the sternum), the soft palate, the oral cavity, arytenoid cartilages, the parotid glands and the submandibular glands was performed.

\subsection{Dose Limitations and Treatment Planning}

Pinnacle $^{2}$ version9 treatment planning system (Philips Radiation Oncology Systems, Fitchburg, WI, USA) was used for treatment planning. PTV 3 of the study and standard treatment plan was generated by using script-based planning. Detailed information on script-based planning have been published earlier [15]. All patients were treated with VMAT (volumetric modulated arc therapy) and also the standard plans were calculated for VMAT treatment.

According to study protocol the following dose limitations should have been respected:

$\mathrm{D}_{\max }$ (maximum dose) of spine: $45 \mathrm{~Gy}$; Dmax of brainstem: $50 \mathrm{~Gy}$, Dmean (mean dose) of the contralateral parotid gland $<26 \mathrm{~Gy}$,

$\mathrm{D}_{\text {mean }}$ of each swallowing structure should have been $<56$ Gy if coverage of target volume was not compromised.

In the standard treatment plans the dose constraints mentioned above were also routinely respected, if possible. Treatment planning was in accordance with the guidelines of the International Commission on Radiation Units and Measurements (ICRU) report 50/83 (http://jicru.oxfordjournals. org/content/10/1.toc) to deliver the prescribed doses to the PTVs while keeping doses to the organs at risk within the constraints or as low as reasonably achievable.

Target volume of all irradiated PTVs and Dmean of ipsilateral and contralateral parotid and submandibular glands as well as swallowing structures were evaluated. Furthermore we assessed the Dmean of all swallowing structures and parotid and submandibular glands with a $3 \mathrm{~mm}$ safety margin in all directions in order to consider daily reposition error and organ movement.

\subsection{Statistical Analysis}

IBM SPSS Version 20 (IBM, Armonk, NY, USA) was used for calculations and descriptive statistics. Mean, maximum and minimum values of each variable and related standard deviation was calculated. Data were compared using the Student's t-test with paired samples (Study treatment plan vs. standard treatment plan). Statistical significance was assumed for $p \leq 0.05$.

\section{Results}

For detailed patient information see Table 1.

No patient was treated in Arm 1, 23/30 (76.7\%) patients in Arm 2 and 7/30 (23.3\%) patients in Arm 3. Mean PTV3 (see Figure 2) in the study treatment plans was $662 \mathrm{~mL}$ (standard deviation: $+/-165 \mathrm{~mL}$; range: 345; $926 \mathrm{~mL}$ ) compared to $1166 \mathrm{~mL}$ (standard deviation: +/- $266 \mathrm{~mL}$; range: 636; $1586 \mathrm{~mL}$ ) in the standard treatment plans $(p<0.000)$.

Mean PTV 2 was $391 \mathrm{~mL}$ (standard deviation: +/- $120 \mathrm{~mL}$; range 170; $598 \mathrm{~mL}$ ) in the study and standard treatment plans. 
Table 1. Patient characteristics.

\begin{tabular}{|c|c|c|}
\hline Characteristics & No. of Patients & $\%$ \\
\hline \multicolumn{3}{|l|}{ Sex } \\
\hline Male & 19 & 63.3 \\
\hline Female & 11 & 36.7 \\
\hline \multicolumn{3}{|l|}{ Age at diagnosis, y } \\
\hline Median & 59 & \\
\hline Range & $40-80$ & \\
\hline \multicolumn{3}{|l|}{ Primary tumor site } \\
\hline Oral cavity & 9 & 30 \\
\hline Oropharynx & 21 & 70 \\
\hline Base of the tongue & 4 & \\
\hline Tonsil & 16 & \\
\hline Other & 1 & \\
\hline \multicolumn{3}{|l|}{ pT classification } \\
\hline $\mathrm{T} 1$ & 10 & 33.3 \\
\hline $\mathrm{T} 2$ & 16 & 53.3 \\
\hline T3 & 4 & 13.3 \\
\hline \multicolumn{3}{|l|}{ pN classification } \\
\hline No & 1 & 3.3 \\
\hline N1 & 9 & 30 \\
\hline $\mathrm{N} 2 \mathrm{a}$ & 10 & 33.3 \\
\hline $\mathrm{N} 2 \mathrm{~b}$ & 10 & 33.3 \\
\hline \multicolumn{3}{|l|}{ Perinodal spread } \\
\hline Yes & 6 & 20 \\
\hline No & 24 & 80 \\
\hline \multicolumn{3}{|l|}{ Lymphangiosis } \\
\hline L0 & 25 & 83.3 \\
\hline L1 & 5 & 16.7 \\
\hline \multicolumn{3}{|l|}{ Hemangiosis } \\
\hline V0 & 28 & 93.3 \\
\hline V1 & 2 & 6.7 \\
\hline \multicolumn{3}{|l|}{ Perineural spread } \\
\hline $\operatorname{Pn} 0$ & 24 & 80 \\
\hline Pn1 & 6 & 20 \\
\hline \multicolumn{3}{|l|}{ Grading } \\
\hline G1 & 0 & 0 \\
\hline G2 & 9 & 30 \\
\hline G3 & 21 & 70 \\
\hline \multicolumn{3}{|l|}{ Tracheostomy } \\
\hline yes & 5 & 16.7 \\
\hline yes, temporary during surgery & 15 & 50 \\
\hline no & 10 & 33.3 \\
\hline \multicolumn{3}{|l|}{ HPV } \\
\hline Positive & 9 & 30 \\
\hline Negative & 16 & 53.3 \\
\hline Not defined & 5 & 16.7 \\
\hline \multicolumn{3}{|l|}{ Neck dissection } \\
\hline Only ipsilateral & 13 & 43.3 \\
\hline Bilateral & 17 & 56.7 \\
\hline \multicolumn{3}{|l|}{ Total removed lymph nodes, $\mathrm{n}$} \\
\hline Median & 32 & \\
\hline Range & $12-90$ & \\
\hline \multicolumn{3}{|l|}{ No. of affected lymph nodes, $n$} \\
\hline Median & 1 & \\
\hline Range & $0-3$ & \\
\hline \multicolumn{3}{|l|}{$\begin{array}{l}\text { Simultaneous Chemotherapy, } \\
\mathrm{n}\end{array}$} \\
\hline Yes & 15 & 50 \\
\hline No & 15 & 50 \\
\hline
\end{tabular}

Mean PTV 1 in the study treatment plans was $170 \mathrm{~mL}$ (standard deviation: $+/-142 \mathrm{~mL}$; range: 0; $486 \mathrm{~mL}$ compared to $208 \mathrm{~mL}$ (standard deviation: $+/-112 \mathrm{~mL}$; range: $69 ; 486 \mathrm{~mL})(p=0.036)$. In seven patients an additional PTV 1 was defined for the standard treatment plan with a mean size of $164 \mathrm{~mL}$ (range 103; $273 \mathrm{~mL}$ ). In the other 23 patients PTV 1 of the study plan was equal to PTV 1 of the standard treatment plan. 


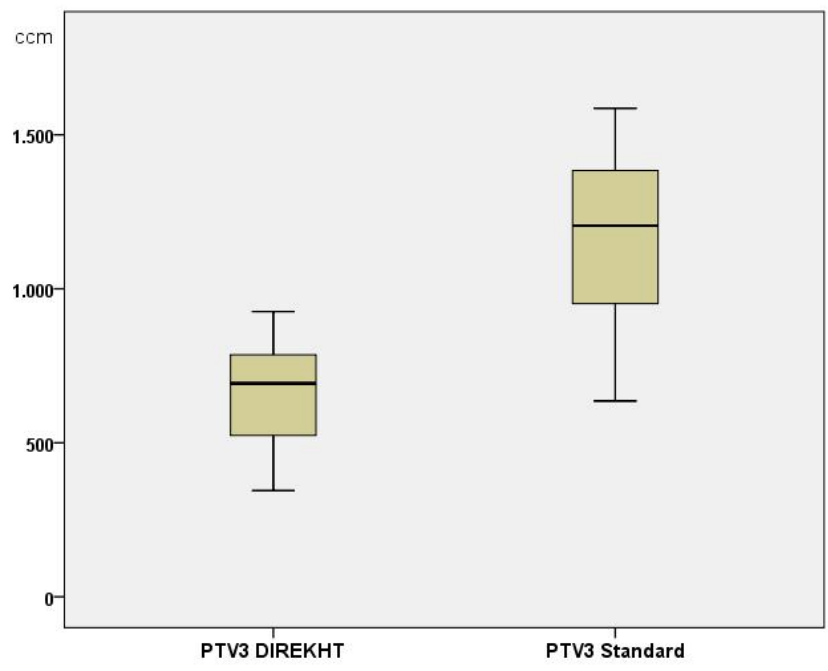

Figure 2. Planning target volume 3 (PTV3) of study treatment plan compared to standard treatment plan.

A significant dose reduction in organs at risk was seen in the complete swallowing apparatus and in all salivary glands, but not in the ipsilateral submandibular gland. In study treatment plans a clinical relevant reduction of mean applied dose of $<56$ Gy was reached in all organs at risk except in soft palate and ipsilateral submandibular gland. Mean differences in organs at risk of more than $10 \mathrm{~Gy}$ difference in study treatment plans compared to standard treatment plans was seen in MCM, ICM, M. cricopharyngeus, glottic and supraglottic larynx, arytenoid cartilages, contralateral submandibular and parotid gland. For detailed information see Table 2. In Table 2 it is also shown that in superior and middle constrictor muscle, in oral cavity, in base of tongue and supraglottic larynx a dose of $<56$ Gy is achieved in study but not in standard treatment plan.

Table 2. Mean doses applied in swallowing apparatus and major salivary glands in study treatment plan compared to standard treatment plan (Organs at risk in which a mean dose of $<56$ Gy is applied in study but not in standard treatment plans are underlined).

\begin{tabular}{|c|c|c|c|c|}
\hline Organs at Risk & $\begin{array}{l}\text { DIREKHT Treatment Plan } \\
\text { Mean Dose Applied (Gy) } \pm \\
\text { Standard Deviation }\end{array}$ & $\begin{array}{l}\text { Standard Treatment Plan } \\
\text { Mean Dose Applied (Gy) } \pm \\
\text { Standard Deviation }\end{array}$ & $p$ Value & $\begin{array}{l}\text { Median Difference } \\
\text { Between Study-and } \\
\text { Standard Treatment Plans } \\
\text { (Gy) (Minimum; } \\
\text { Maximum) }\end{array}$ \\
\hline $\begin{array}{l}\text { Superior constrictor muscle } \\
\text { (SCM) }\end{array}$ & $\underline{53.8 \pm 6.4}$ & $61.3 \pm 2.0$ & 0.000 & $6.9(-0.7 ; 20.5)$ \\
\hline $\begin{array}{l}\text { Middle constrictor muscle } \\
\text { (MCM) }\end{array}$ & $\underline{47.2 \pm 9.3}$ & $59.3 \pm 3.0$ & 0.000 & $13.1(-0.7 ; 23.3)$ \\
\hline $\begin{array}{l}\text { Inferior constrictor muscle } \\
\text { (ICM) }\end{array}$ & $35.9 \pm 9.5$ & $53.6 \pm 5.0$ & 0.000 & $18.2(2.3 ; 32.3)$ \\
\hline Constrictor muscles & $\underline{48.8 \pm 6.6}$ & $59.4 \pm 2.2$ & 0.000 & $10.7(2.2 ; 20.9)$ \\
\hline Musculus cricopharyngeus & $\overline{33.6 \pm 8.6}$ & $48.7 \pm 7.6$ & 0.000 & $15.5(0.9 ; 29.9)$ \\
\hline Esophagus inlet muscle (EIM) & $37.2 \pm 11.1$ & $45.5 \pm 10.0$ & 0.000 & $6.9(-1.4 ; 26.5)$ \\
\hline SCM to EIM & $46.3 \pm 6.4$ & $57.2 \pm 2.9$ & 0.000 & $10.5(2.7 ; 20.9)$ \\
\hline Cervical esophagus & $29.1 \pm 8.9$ & $33.5 \pm 6.2$ & 0.002 & $3.5(-8.3 ; 19.7)$ \\
\hline Soft palate & $59.1 \pm 5.1$ & $62.0 \pm 2.0$ & 0.002 & $1.0(-1.9 ; 13.9)$ \\
\hline Base of tongue & $\underline{55.6 \pm 7.7}$ & $60.7 \pm 2.3$ & 0.000 & $3.8(-2.1 ; 19.9)$ \\
\hline Oral cavity & $\overline{52.2 \pm 8.5}$ & $57.1 \pm 4.5$ & 0.000 & $5.7(-2.7 ; 16.2)$ \\
\hline Glottic larynx & $30.5 \pm 11.4$ & $49.4 \pm 8.5$ & 0.000 & $17.2(1.5 ; 35.6)$ \\
\hline Supraglottic larynx & $\underline{41.7 \pm 11.2}$ & $57.0 \pm 4.2$ & 0.000 & $16.4(-0.2 ; 26.4)$ \\
\hline Arytenoid cartilages & $\overline{30.4 \pm 10.9}$ & $50.1 \pm 7.8$ & 0.000 & $19.0(2.3 ; 34.8)$ \\
\hline Ipsilateral parotid gland & $38.9 \pm 7.7$ & $40.1 \pm 7.5$ & 0.002 & $1.5(-3.6 ; 3.9)$ \\
\hline Contralateral parotid gland & $7.4 \pm 2.2$ & $21.5 \pm 2.8$ & 0.000 & $15.1(6.6 ; 20.4)$ \\
\hline Total parotid gland & $23.5 \pm 4.9$ & $31.1 \pm 4.8$ & 0.000 & $8.0(3.0 ; 12.2)$ \\
\hline Ipsilateral submandibular gland & $60.7 \pm 3.7$ & $62.3 \pm 5.6$ & 0.088 & $0.2(-1.1 ; 9.2)$ \\
\hline $\begin{array}{c}\text { Contralateral submandibular } \\
\text { gland }\end{array}$ & $17.8 \pm 13.8$ & $53.7 \pm 2.8$ & 0.000 & $41.5(11.4 ; 45.0)$ \\
\hline Total submandibular gland & $38.4 \pm 7.8$ & $57.9 \pm 2.0$ & 0.000 & $21.7(5.7 ; 28.7)$ \\
\hline
\end{tabular}


Dose differences in organs at risk surrounded by a $3 \mathrm{~mm}$ safety margin in all directions provided equal results, see Table S2. Comparing dosimetric values of patients treated in Arm 2 and patients treated in Arm 3 it is obvious that in organs at risk near or in the primary tumor region (e.g., soft palate, $\mathrm{scm}$, base of tongue, oral cavity) a further dose reduction is reached by limitating applied dose in the primary tumor region to $56 \mathrm{~Gy}$ in Arm 3. Therefore mean dose in all organs at risk is under $56 \mathrm{~Gy}$ in patients treated in Arm3 (see Table S3). Figure 3 demonstrates a dose reduction in the primary tumor region with ipsilateral elective neck irradiation.

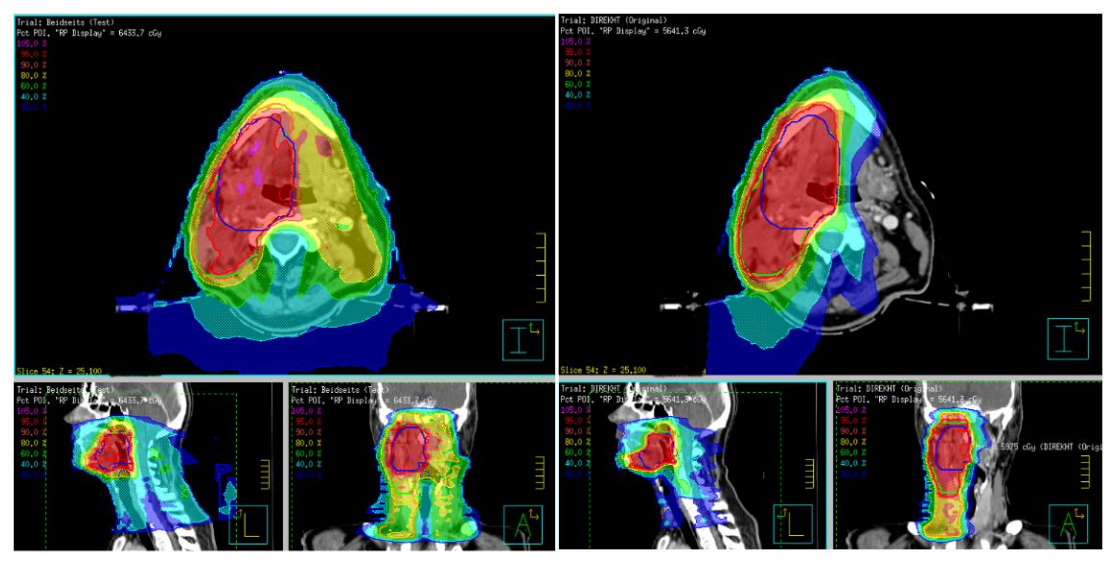

(a)

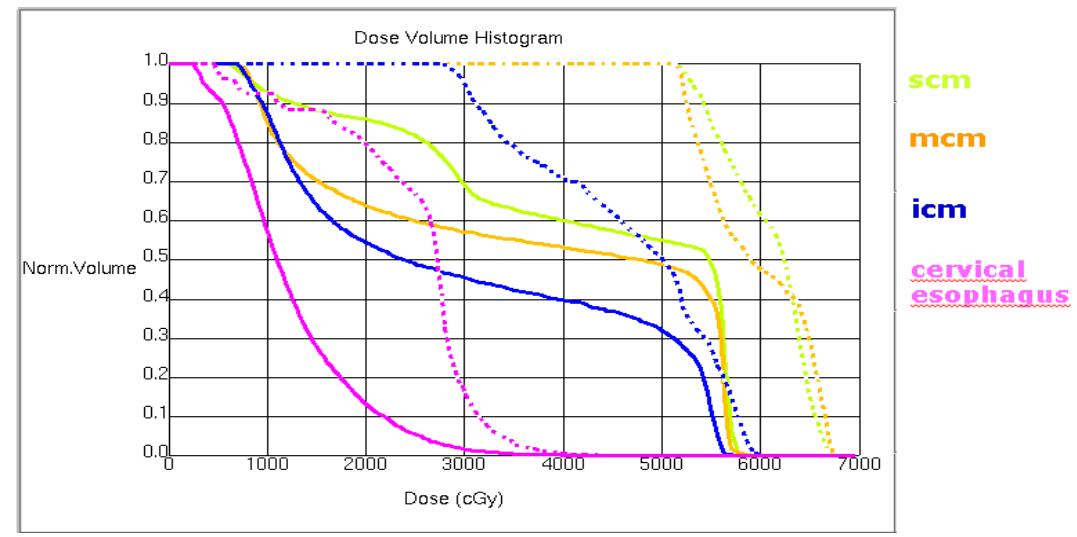

(b)

Figure 3. Male patient with a HPV-associated tonsillar carcinoma on the right side; TNM according to 7th edition of TNM classification: pT1pN2b (3/29 without ECS) L0 V0 Pn0 R0 cM0. According to study protocol this patient was treated with a reduced radiotherapy dose of $56 \mathrm{~Gy}$ in the primary tumor region only with ipsilateral elective neck irradiation. In the standard treatment plan, the patient would have received a total dose of $64 \mathrm{~Gy}$ in the primary tumor region and bilateral elective neck irradiation. (a) Dose distribution of the standard and study treatment plan (blue contour within the high-dose-volume is the boost which is additionally applied in the standard but not in the study treatment plan) with the study treatment plan showing especially significant reduced dose in contralateral neck and pharyngeal structures. In the study treatment plan most parts of the swallowing structures receive less than $30 \%$ of the prescribed dose while in the standard treatment plan large parts of the swallowing apparatus receive 40 to $60 \%$ of prescribed dose. (b) Dose-volume histogram of superior (light green), medial (orange), inferior (blue) constrictor muscle and cervical esophagus (pink) shows significantly smaller doses in constrictor muscles and cervical esophagus in the study (solid line) compared to the standard (dotted line) treatment plan. 


\section{Discussion}

This plan comparison study shows a significant dose reduction for organs at risk, especially regarding the swallowing apparatus and contralateral submandibular and parotid glands by de-intensification of radiotherapy in a low-risk patient population with head and neck cancer in the postsurgical situation. Moreover this is not only a fictive planning study but a real world setting. Patients have been irradiated with innovative optimized study treatment plans. In a previous study this low-risk patient population was evaluated retrospectively [8]. Even though patients being treated with standard-of-care radiotherapy showed excellent locoregional control rates of more than $95 \%$ after 5 years and a cumulative incidence of distant metastases of less than $6 \%$, about $13 \%$ of the patients suffered from a second malignancy 5 years after diagnosis of head and neck cancer and more than $20 \%$ of the patients suffer from a high rate of therapy induced late side effects.

Twenty-one percent of the patients showed a grade III dysphagia and about $20 \%$ a grade II xerostomia. [8] Considering the high incidence of second cancer and the severe rate of therapy induced late side effects, the current prospective trial was started for this low-risk patient population. In case of xerostomia, there is evidence for dose-volume relationships linking the dose to the major salivary glands to a dry mouth and clear dose limits exist for the parotid gland [16]. There are also several studies [17-27] that demonstrate a dose-volume-relationship between late dysphagia and the radiation dose delivered to specific parts of the swallowing apparatus. A correlation between post-treatment swallowing function and the radiation dose to various structures of the swallowing apparatus, such as the constrictor muscles in general [17,28], superior PCM [18-22,27], middle PCM [18-20,22,23], inferior PCM [18,24,25], CPM [25], supraglottic larynx [17,23,26,28], the larynx in general [18,24,28], oral cavity [21] and the EIM [26], esophagus [17], and soft palate [24,27] had been reported. However different swallowing structures were contoured in these studies and the definition of the corresponding anatomically morphological CT boundaries have varied across different studies. The results of these studies are discrepant regarding the relevant swallowing structures to be spared and the optimal dose needed to be delivered. In view of these discrepant results it appears likely that optimization of posttreatment swallowing function can be achieved realistically by protecting either a complete part or coherent parts of the swallowing apparatus and not a single special structure. Consequently, one could spare either cranial or caudal portions of the swallowing structures, depending on tumor location and lymph node involvement. Dose-volume-relationships vary, but it has to be assumed that mean doses of less than 60 Gy or better less than 56 Gy should be applied in the swallowing apparatus to reach better functional outcome for the patients [29]. Indeed, the dosimetric gain that was reached in the study treatment plans was surprisingly high. Large parts of the swallowing apparatus were irradiated with a mean dose of less than 56 Gy and mean dose in contralateral submandibular gland was less than $20 \mathrm{~Gy}$ in most patients. According to reported dose-volume-relationships $[16,29]$ these dose reductions in study treatment plans should lead to an an improved outcome for the patients regarding late side-effects like xerostomia or dysphagia.

Prospective randomized trials have already shown the benefit of parotid sparing IMRT $[30,31]$ Feng et al. [32,33] showed in a non-randomized trial that dose reduction in the swallowing apparatus led to reduced late dysphagia in patients with oropharyngeal cancer after definitive radiotherapy. But results of prospective randomized trials [34] investigating swallowing sparing IMRT are still pending.

Dose reduction in study treatment plans compared to standard treatment plans was especially seen in contralateral submandibular and parotid gland, medial/inferior constrictor muscle, musculus cricopharyngeus and larynx. In case of all primary tumors being localized either in the oral cavity or oropharynx the absolute dose reduction in the oral cavity, base of tongue and soft palate is much lower.

Due to the inclusion of tracheostoma or tracheostomy in PTV 2 and PTV 3 the cervical esophagus may not be spared to the maximal extent. Therefore especially in patients with tracheostoma or tracheostomy during surgery there is no difference between study and standard treatment plan resulting in a relatively low mean difference of delivered dose comparing standard and study treatment plan. The contralateral submandibular gland was the OAR which could be spared most in experimental 
treatment plans. That is due to the fact that no patient was treated in Arm 1 and therefore all of the 30 patients received ipsilateral elective node irradiation only. There is evidence of a relationship between dose delivered in the contralateral submandibular gland and percutaneous endoscopic gastrostomy tube dependence after radiotherapy [35]. But there is also a percentage of patients who underwent submandibulectomy on both sides during primary tumor surgery and neck dissection. The influence of submandibulectomy and dose-volume relationships on swallowing outcome after radiotherapy will be considered in the final analysis of the trial.

It has to be mentioned that dosimetric results might not represent those of the planned entire cohort of the ongoing trial as none of the first 30 patients included in this treatment study were treated in Arm1. Currently there are hardly any patients meeting inclusion citeria for Arm1 and that less than $10 \%$ of the included patients in the DIREKHT trial were treated in Arm 1. Only the first 30 patients of the leading study centre were included in this treatment planning study, because creating a standard treatment plan and comparing it to study treatment plan was not part of the study protocol and therefore this information was not available from the other participating centres. But in our opinion this treatment plan comparison was important for quality assurance and to find out if if the dose constraints and target volumes of the study protocol might be improved. And for answering this question we think 30 patients were adequate.

Advances in head and neck surgery have led from radical neck dissection to selective neck dissection in selected patients with squamous cell carcinoma of the oral cavity, pharynx and larynx [36]. In radiation oncology modern techniques such as IMRT or VMAT combined with image-guidance allow a higher precision in dose application and therefore individualized treatment approaches should be investigated [37-40]. The aim of the DIREKHT trial is to reduce late toxicity after postoperative radiotherapy without increasing locoregional failure. All patients included in this study receive swallowing endoscopy before radiotherapy and 6 and 12 months after the end of radiotherapy. Moreover patients answer quality of life questionnaires at fixed dates. An interim analysis was planned after the enrolment of the first 100 patients and is presently ongoing. But at the moment results of locoregional control rate and late side effects, especially xerostomia and dysphagia are still pending and it is currently unknown if smaller PTVs and lower doses in the swallowing apparatus and contralateral submandibular and parotid gland lead to less long-term side-effects and better quality of life. It is important to bear in mind that in this analysis only a small number of patients has been included and this might influence statistical observation. Moreover there are more factors influencing long-term dysphagia in patients with head and neck cancer, e.g., smoking [24,25], primary tumor site [18,21,23], T-stage [18,23,41], alcohol consumption [27] and pretreatment dysphagia [18,23,41]. These factors and even more patient-, tumor and treatment-related parameters will be considered in the final analysis of the study.

\section{Conclusions}

De-intensification of radiotherapy in a pre-defined low-risk patient population with head and neck cancer leads to significant smaller planning target volumes and significant lower doses in parts of the swallowing apparatus and the contralateral salivary glands.

Supplementary Materials: The following are available online at http://www.mdpi.com/2072-6694/12/3/538/s1, Table S1: Contouring guidelines of elective neck nodes according to study protocol, Table S2: Mean Doses applied in swallowing apparatus and major salivary glands (each surrounded by a $3 \mathrm{~mm}$ margin) in study treatment plan compared to standard treatment plan, Table S3: Mean Doses applied in swallowing apparatus and major salivary glands in arm 2 and 3 of study population.

Author Contributions: Conceptualization: M.H. (Marlen Haderlein), S.S. (Stefan Speer), O.O., S.L., M.H. (Markus Hecht), S.S. (Sabine Semrau), B.F., C.S., H.I., M.K., R.F.; Methodology: M.H. (Marlen Haderlein), S.S. (Stefan Speer), O.O.; Validation: M.H. (Marlen Haderlein), S.S. (Stefan Speer), R.F., B.F.; Formal Analysis: M.H. (Marlen Haderlein), S.S. (Stefan Speer); Investigation: M.H. (Marlen Haderlein), S.S. (Stefan Speer); Ressources: R.F.; Data Curation: M.H. (Marlen Haderlein); Writing-Original Draft Preparation: M.H. (Marlen Haderlein); Writing- Review \& Editing: M.H. (Marlen Haderlein), S.S. (Stefan Speer), O.O., S.L., M.H. (Markus Hecht), S.S. (Sabine Semrau), C.S., H.I., M.K., R.F., B.F.; Visualization: M.H. (Marlen Haderlein); Supervision: R.F.; Project Administration: M.H. (Marlen Haderlein), R.F. All authors have read and agreed to the published version of the manuscript. 
Funding: This research received no external funding.

Acknowledgments: The authors thank the participating study centres of the DIREKHT trial, the Departments of Radiation Oncology of (in alphabetical order): University hospital (Charité), Berlin, Germany; Hospital, Chemnitz, Germany; University hospital, Frankfurt, Germany; Hospital “Ordensklinikum Barmherzige Schwestern”, Linz, Austria; University hospital, Marburg, Germany; University hospital, Regensburg, Germany; Hospital "St-Vinzenz", Stuttgart, Germany.

Conflicts of Interest: On behalf of all authors the corresponding author states that there is no conflict of interest.

\section{References}

1. Contreras, J.A.; Spencer, C.; de Wees, T.; Haughey, B.; Henke, L.E.; Chin, R.I.; Paniello, R.; Rich, J.; Jackson, R.; Oppelt, P.; et al. Eliminating Postoperative Radiation to the Pathologically Node-Negative Neck: Long-Term Results of a Prospective Phase II Study. J. Clin. Oncol. Off. J. Am. Soc. Clin. Oncol. 2019. [CrossRef] [PubMed]

2. Huang, S.H.; Waldron, J.; Bratman, S.V.; Su, J.; Kim, J.; Bayley, A.; Cho, J.; Giuliani, M.; Hope, A.; Ringash, J.; et al. Re-evaluation of Ipsilateral Radiation for T1-T2N0-N2b Tonsil Carcinoma at the Princess Margaret Hospital in the Human Papillomavirus Era, 25 Years Later. Int. J. Radiat. Oncol. Biol. Phys. 2017, 98, 159-169. [CrossRef] [PubMed]

3. Wirtz, M.M.; Temming, S.; Kocher, M.; Kunze, S.; Semrau, R. Low risk of contralateral lymph node recurrence in lateralized head and neck carcinoma after postoperative ipsilateral radiotherapy. Strahlentherapie und Onkologie Organ der Deutschen Rontgengesellschaft 2019. [CrossRef] [PubMed]

4. Cooper, J.S.; Pajak, T.F.; Forastiere, A.A.; Jacobs, J.; Campbell, B.H.; Saxman, S.B.; Kish, J.A.; Kim, H.E.; Cmelak, A.J.; Rotman, M.; et al. Postoperative concurrent radiotherapy and chemotherapy for high-risk squamous-cell carcinoma of the head and neck. N. Engl. J. Med. 2004, 350, 1937-1944. [CrossRef] [PubMed]

5. Bernier, J.; Domenge, C.; Ozsahin, M.; Matuszewska, K.; Lefebvre, J.L.; Greiner, R.H.; Giralt, J.; Maingon, P.; Rolland, F.; Bolla, M.; et al. Postoperative irradiation with or without concomitant chemotherapy for locally advanced head and neck cancer. N. Engl. J. Med. 2004, 350, 1945-1952. [CrossRef]

6. Fietkau, R.; Lautenschläger, C.; Sauer, R.; Dunst, J.; Becker, A.; Wendt, M.B.; Grüschow, K.; Hess, C.; Budach, V.; Iro, H.; et al. Postoperative concurrent radiochemotherapy versus radiotherapy in high-risk SCCA of the head and neck: Results of the German phase III trial ARO 96-3. J. Clin. Oncol. 2006, 24, 5507. [CrossRef]

7. Peters, L.J.; Goepfert, H.; Ang, K.K.; Byers, R.M.; Maor, M.H.; Guillamondegui, O.; Morrison, W.H.; Weber, R.S.; Garden, A.S.; Frankenthaler, R.A.; et al. Evaluation of the dose for postoperative radiation therapy of head and neck cancer: First report of a prospective randomized trial. Int. J. Radiat. Oncol. Biol. Phys. 1993, 26, 3-11. [CrossRef]

8. Onbasi, Y.; Lettmaier, S.; Hecht, M.; Semrau, S.; Iro, H.; Kesting, M.; Fietkau, R.; Haderlein, M. Is there a patient population with squamous cell carcinoma of the head and neck region who might benefit from de-intensification of postoperative radiotherapy? A monocentric retrospective analysis of a previously defined low-risk patient population treated with standard-of-care radiotherapy. Strahlentherapie und Onkologie Organ der Deutschen Rontgengesellschaft 2019. [CrossRef]

9. Rathod, S.; Livergant, J.; Klein, J.; Witterick, I.; Ringash, J. A systematic review of quality of life in head and neck cancer treated with surgery with or without adjuvant treatment. Oral Oncol. 2015, 51, 888-900. [CrossRef]

10. Oskam, I.M.; Verdonck-de Leeuw, I.M.; Aaronson, N.K.; Witte, B.I.; de Bree, R.; Doornaert, P.; Langendijk, J.A.; Leemans, C.R. Prospective evaluation of health-related quality of life in long-term oral and oropharyngeal cancer survivors and the perceived need for supportive care. Oral Oncol. 2013, 49, 443-448. [CrossRef]

11. Mehanna, H.M.; Morton, R.P. Deterioration in quality-of-life of late (10-year) survivors of head and neck cancer. Clin. Otolaryngol. Off. J. Ent-Uk; Off. J. Neth. Soc. Oto-Rhino-Laryngol. Cervico-Facial Surg. 2006, 31, 204-211. [CrossRef] [PubMed]

12. Bjordal, K.; de Graeff, A.; Fayers, P.M.; Hammerlid, E.; van Pottelsberghe, C.; Curran, D.; Ahlner-Elmqvist, M.; Maher, E.J.; Meyza, J.W.; Bredart, A.; et al. A 12 country field study of the EORTC QLQ-C30 (version 3.0) and the head and neck cancer specific module (EORTC QLQ-H\&N35) in head and neck patients. EORTC Quality of Life Group. Eur. J. Cancer 2000, 36, 1796-1807. [CrossRef] [PubMed] 
13. Mowry, S.E.; Ho, A.; Lotempio, M.M.; Sadeghi, A.; Blackwell, K.E.; Wang, M.B. Quality of life in advanced oropharyngeal carcinoma after chemoradiation versus surgery and radiation. Laryngoscope 2006, 116, 1589-1593. [CrossRef] [PubMed]

14. Christianen, M.E.; Langendijk, J.A.; Westerlaan, H.E.; van de Water, T.A.; Bijl, H.P. Delineation of organs at risk involved in swallowing for radiotherapy treatment planning. Radiother. Oncol. J. Eur. Soc. Ther. Radiol. Oncol. 2011, 101, 394-402. [CrossRef]

15. Speer, S.; Klein, A.; Kober, L.; Weiss, A.; Yohannes, I.; Bert, C. Automation of radiation treatment planning: Evaluation of head and neck cancer patient plans created by the Pinnacle(3) scripting and Auto-Planning functions. Strahlentherapie und Onkologie Organ der Deutschen Rontgengesellschaft 2017, 193, 656-665. [CrossRef]

16. Tribius, S.; Sommer, J.; Prosch, C.; Bajrovic, A.; Muenscher, A.; Blessmann, M.; Kruell, A.; Petersen, C.; Todorovic, M.; Tennstedt, P. Xerostomia after radiotherapy. What matters-mean total dose or dose to each parotid gland? Strahlentherapie und Onkologie Organ der Deutschen Rontgengesellschaft 2013, 189, $216-222$. [CrossRef]

17. Eisbruch, A.; Kim, H.M.; Feng, F.Y.; Lyden, T.H.; Haxer, M.J.; Feng, M.; Worden, F.P.; Bradford, C.R.; Prince, M.E.; Moyer, J.S.; et al. Chemo-IMRT of oropharyngeal cancer aiming to reduce dysphagia: Swallowing organs late complication probabilities and dosimetric correlates. Int. J. Radiat. Oncol. Biol. Phys. 2011, 81, e93-e99. [CrossRef]

18. Caudell, J.J.; Schaner, P.E.; Desmond, R.A.; Meredith, R.F.; Spencer, S.A.; Bonner, J.A. Dosimetric factors associated with long-term dysphagia after definitive radiotherapy for squamous cell carcinoma of the head and neck. Int. J. Radiat. Oncol. Biol. Phys. 2010, 76, 403-409. [CrossRef]

19. Teguh, D.N.; Levendag, P.C.; Noever, I.; van Rooij, P.; Voet, P.; van der Est, H.; Sipkema, D.; Sewnaik, A.; Baatenburg de Jong, R.J.; de la Bije, D.; et al. Treatment techniques and site considerations regarding dysphagia-related quality of life in cancer of the oropharynx and nasopharynx. Int. J. Radiat. Oncol. Biol. Phys. 2008, 72, 1119-1127. [CrossRef]

20. Levendag, P.C.; Teguh, D.N.; Voet, P.; van der Est, H.; Noever, I.; de Kruijf, W.J.; Kolkman-Deurloo, I.K.; Prevost, J.B.; Poll, J.; Schmitz, P.I.; et al. Dysphagia disorders in patients with cancer of the oropharynx are significantly affected by the radiation therapy dose to the superior and middle constrictor muscle: A dose-effect relationship. Radiother. Oncol. J. Eur. Soc. Ther. Radiol. Oncol. 2007, 85, 64-73. [CrossRef]

21. Schwartz, D.L.; Hutcheson, K.; Barringer, D.; Tucker, S.L.; Kies, M.; Holsinger, F.C.; Ang, K.K.; Morrison, W.H.; Rosenthal, D.I.; Garden, A.S.; et al. Candidate dosimetric predictors of long-term swallowing dysfunction after oropharyngeal intensity-modulated radiotherapy. Int. J. Radiat. Oncol. Biol. Phys. 2010, 78, 1356-1365. [CrossRef] [PubMed]

22. Deantonio, L.; Masini, L.; Brambilla, M.; Pia, F.; Krengli, M. Dysphagia after definitive radiotherapy for head and neck cancer. Correlation of dose-volume parameters of the pharyngeal constrictor muscles. Strahlentherapie und Onkologie Organ der Deutschen Rontgengesellschaft 2013, 189, 230-236. [CrossRef] [PubMed]

23. Dirix, P.; Abbeel, S.; Vanstraelen, B.; Hermans, R.; Nuyts, S. Dysphagia after chemoradiotherapy for head-and-neck squamous cell carcinoma: Dose-effect relationships for the swallowing structures. Int. J. Radiat. Oncol. Biol. Phys. 2009, 75, 385-392. [CrossRef] [PubMed]

24. Caglar, H.B.; Tishler, R.B.; Othus, M.; Burke, E.; Li, Y.; Goguen, L.; Wirth, L.J.; Haddad, R.I.; Norris, C.M.; Court, L.E.; et al. Dose to larynx predicts for swallowing complications after intensity-modulated radiotherapy. Int. J. Radiat. Oncol. Biol. Phys. 2008, 72, 1110-1118. [CrossRef]

25. Li, B.; Li, D.; Lau, D.H.; Farwell, D.G.; Luu, Q.; Rocke, D.M.; Newman, K.; Courquin, J.; Purdy, J.A.; Chen, A.M. Clinical-dosimetric analysis of measures of dysphagia including gastrostomy-tube dependence among head and neck cancer patients treated definitively by intensity-modulated radiotherapy with concurrent chemotherapy. Radiat. Oncol. 2009, 4, 52. [CrossRef]

26. Jensen, K.; Lambertsen, K.; Grau, C. Late swallowing dysfunction and dysphagia after radiotherapy for pharynx cancer: Frequency, intensity and correlation with dose and volume parameters. Radiother. Oncol. J. Eur. Soc. Ther. Radiol. Oncol. 2007, 85, 74-82. [CrossRef]

27. Haderlein, M.; Semrau, S.; Ott, O.; Speer, S.; Bohr, C.; Fietkau, R. Dose-dependent deterioration of swallowing function after induction chemotherapy and definitive chemoradiotherapy for laryngopharyngeal cancer. Strahlentherapie und Onkologie Organ der Deutschen Rontgengesellschaft 2014, 190, 192-198. [CrossRef] 
28. Mortensen, H.R.; Jensen, K.; Aksglaede, K.; Behrens, M.; Grau, C. Late dysphagia after IMRT for head and neck cancer and correlation with dose-volume parameters. Radiother. Oncol. J. Eur. Soc. Ther. Radiol. Oncol. 2013, 107, 288-294. [CrossRef]

29. Charters, E.K.; Bogaardt, H.; Freeman-Sanderson, A.L.; Ballard, K.J. Systematic review and meta-analysis of the impact of dosimetry to dysphagia and aspiration related structures. Head Neck 2019, 41, 1984-1998. [CrossRef]

30. Nutting, C.M.; Morden, J.P.; Harrington, K.J.; Urbano, T.G.; Bhide, S.A.; Clark, C.; Miles, E.A.; Miah, A.B.; Newbold, K.; Tanay, M.; et al. Parotid-sparing intensity modulated versus conventional radiotherapy in head and neck cancer (PARSPORT): A phase 3 multicentre randomised controlled trial. Lancet Oncol. 2011, 12, 127-136. [CrossRef]

31. Kam, M.K.; Leung, S.F.; Zee, B.; Chau, R.M.; Suen, J.J.; Mo, F.; Lai, M.; Ho, R.; Cheung, K.Y.; Yu, B.K.; et al. Prospective randomized study of intensity-modulated radiotherapy on salivary gland function in early-stage nasopharyngeal carcinoma patients. J. Clin. Oncol. Off. J. Am. Soc. Clin. Oncol. 2007, 25, 4873-4879. [CrossRef] [PubMed]

32. Feng, F.Y.; Kim, H.M.; Lyden, T.H.; Haxer, M.J.; Worden, F.P.; Feng, M.; Moyer, J.S.; Prince, M.E.; Carey, T.E.; Wolf, G.T.; et al. Intensity-modulated chemoradiotherapy aiming to reduce dysphagia in patients with oropharyngeal cancer: Clinical and functional results. J. Clin. Oncol. Off. J. Am. Soc. Clin. Oncol. 2010, 28, 2732-2738. [CrossRef] [PubMed]

33. Vainshtein, J.M.; Moon, D.H.; Feng, F.Y.; Chepeha, D.B.; Eisbruch, A.; Stenmark, M.H. Long-term quality of life after swallowing and salivary-sparing chemo-intensity modulated radiation therapy in survivors of human papillomavirus-related oropharyngeal cancer. Int. J. Radiat. Oncol. Biol. Phys. 2015, 91, 925-933. [CrossRef] [PubMed]

34. Petkar, I.; Rooney, K.; Roe, J.W.; Patterson, J.M.; Bernstein, D.; Tyler, J.M.; Emson, M.A.; Morden, J.P.; Mertens, K.; Miles, E.; et al. DARS: A phase III randomised multicentre study of dysphagia- optimised intensity- modulated radiotherapy (Do-IMRT) versus standard intensity- modulated radiotherapy (S-IMRT) in head and neck cancer. BMC Cancer 2016, 16, 770. [CrossRef] [PubMed]

35. Gensheimer, M.F.; Nyflot, M.; Laramore, G.E.; Liao, J.J.; Parvathaneni, U. Contribution of submandibular gland and swallowing structure sparing to post-radiation therapy PEG dependence in oropharynx cancer patients treated with split-neck IMRT technique. Radiat. Oncol. 2016, 11, 151. [CrossRef] [PubMed]

36. Rodrigo, J.P.; Grilli, G.; Shah, J.P.; Medina, J.E.; Robbins, K.T.; Takes, R.P.; Hamoir, M.; Kowalski, L.P.; Suarez, C.; Lopez, F.; et al. Selective neck dissection in surgically treated head and neck squamous cell carcinoma patients with a clinically positive neck: Systematic review. Eur. J. Surg. Oncol. J. Eur. Soc. Surg. Oncol. Br. Assoc. Surg. Oncol. 2018, 44, 395-403. [CrossRef] [PubMed]

37. Tiong, A.; Lao, L.; MacKean, J.; Goonetilleke, M.; Kron, T. Faculty of Radiation Oncology Position Paper on the use of Image-Guided Radiation Therapy. J. Med. Imaging Radiat. Oncol. 2016, 60, 772-780. [CrossRef]

38. Nutting, C.M. Intensity Modulated Radiotherapy (IMRT) in head and neck cancers-An overview. Gulf J. Oncol. 2012, 12, 17-26.

39. Ursino, S.; D'Angelo, E.; Mazzola, R.; Merlotti, A.; Morganti, R.; Cristaudo, A.; Paiar, F.; Musio, D.; Alterio, D.; Bacigalupo, A.; et al. A comparison of swallowing dysfunction after three-dimensional conformal and intensity-modulated radiotherapy: A systematic review by the Italian Head and Neck Radiotherapy Study Group. Strahlentherapie und Onkologie Organ der Deutschen Rontgengesellschaft 2017, 193, 877-889. [CrossRef]

40. van der Veen, J.; Nuyts, S. Can Intensity-Modulated-Radiotherapy Reduce Toxicity in Head and Neck Squamous Cell Carcinoma? Cancers 2017, 9, 135. [CrossRef]

41. Mortensen, H.R.; Overgaard, J.; Jensen, K.; Specht, L.; Overgaard, M.; Johansen, J.; Evensen, J.F.; Andersen, E.; Andersen, L.J.; Hansen, H.S.; et al. Factors associated with acute and late dysphagia in the DAHANCA 6 \& 7 randomized trial with accelerated radiotherapy for head and neck cancer. Acta Oncol. 2013, 52, 1535-1542. [CrossRef] [PubMed]

(C) 2020 by the authors. Licensee MDPI, Basel, Switzerland. This article is an open access article distributed under the terms and conditions of the Creative Commons Attribution (CC BY) license (http://creativecommons.org/licenses/by/4.0/). 